\title{
The use of exosome carrier to augmentation of Helicobacter pylori infection treatment
}

\author{
Saeideh Gholamzadeh Khoei ${ }^{1}$, Hamid Sadeghi ${ }^{2}$, Massoud Saidijam ${ }^{1}$ \\ ${ }^{1}$ Department of Medical Biotechnology, School of Advanced Medical Sciences and Technologies, Hamadan University of Medical Sciences, \\ Hamadan, Iran; ${ }^{2}$ Department of Microbiology and Virology, School of Medicine, Zanjan University of Medical Sciences, Zanjan, Iran \\ Correspondence to: Professor Massoud Saidijam. Department of Medical Biotechnology, School of Advanced Medical Sciences and Technologies, \\ Hamadan University of Medical Sciences, Mahdieh St. Hamadan, Iran. Email: sjam110@yahoo.com.
}

Received: 17 June 2020; Accepted: 08 December 2020; Published: 24 December 2020.

doi: $10.21037 /$ sci-2020-028

View this article at: http://dx.doi.org/10.21037/sci-2020-028

Helicobacter pylori (H. pylori) is a stomach pathogen that half of the world's population is conjectured to be tangled in this gram-negative bacterium (1). It is generally obtained in babyhood, and when left untreated commonly continues for the host's lifetime (2). The early role of $H$. pylori in the peptic lesion and gastric cancer expansion was established and admitted by the medic community as recently as the 1980s $(3,4)$. To retain the chronic form of infection the bacterium changes tissue morphology and physiology by the transfer of virulence factors like the CagA, VacA toxins, and $\gamma$-glutamyltranspeptidase (GGT) enzyme that result in worsening the pathology of the infection $(5,6)$. General standard eradication strategies use two antibiotics and an acid-suppressing drug, now usually completed with bismuth (3). Although the usage of antibiotics throughout the previous decades and improved health conditions has forcefully decreased $H$. pylori prevalence, infection frequency remains high on a universal measure (7). A longsome antibiotic therapy against $H$. pylori infection is growing to start to fail, and innovative strategies towards treatment need to be taken (8). In addition to the concerns on diminishing eradication efficiencies during the burdensome treatment with several broad-spectrum antibiotics, there are the health concerns about adverse impacts on the commensal microbiota $(9,10)$. Especially in the treatment of pediatric $H$. pylori, the synchronic loss of the gut flora by extensive antibiotics is a major challenge. Furthermore, reducing eradication effectiveness, off-target impacts of lengthy broad-spectrum antibiotic therapies, and the desire of a more regular eradication in asymptomatic H. pylori carriers to reduce gastric cancer occurrence spur a search for finding a smarter remedial option to deliver of antibiotic in local $(3,11)$. A direct drug delivery is an effective approach to increase efficacy therapy helicobacter pylori infection. Recently, considerable research has been focused on exosomes as nanocarriers for direct drug delivery. Exosomes are nanosized (30-150 nm) lipid bilayer particles of endosomal source. They belong to the extracellular vesicles (EVs) that secrete by multiple cell types and involve in cell-cell communication or intracellular signaling (12). The membrane building of exosome makes them have an innate potency to fuse with the membrane of the acceptor organelle or plasma cell, and play a major role in the transport of bioactive cellular cargos such as proteins, lipids, and RNAs at a neighbor or distant cell (13). Indeed, exosomes as safe and natural drug delivery carriers able to trip in extracellular fluids and deliver various therapeutic agents to target cells with high efficiency (14). Furthermore, the ideal direct drug delivery carrier should be able to site-specific delivery of loaded therapeutics, avoid premature degradation through the body's immune defense system and controlled release of it upon selective stimuli (15). In addition to these properties, exosomes have manifested many advantages in biocompatibility terms and reduced clearance levels in comparison with other direct drug delivery carrier. Moreover, they show slight long-term accumulation in various organs or tissue, with synchronous low systemic toxicity $(16,17)$. In recent years, exosomebased drug (synthetic or biological molecules) delivery strategies have been used in a wide variety of disorders including cancer, various infections, neurodegenerative and cardiovascular disorders (18). For example, the exosomes derived from EL-4 cells have been used to deliver curcumin and via enhancing of anti-inflammatory effects of curcumin 
led to treat of inflammatory disease (19). Also, through exosome parental cells engineering can improve their targeting ability to express the appropriate modification on the surface of the exosome. In this regard, one study demonstrated that the expressing a kind of high affinity peptide to integrin $\alpha v \beta 3$ [c(RGDyK)] on MSC-derived exosome surface led to conjugate it to the reactive cerebral related vascular endothelial cells after ischemia, so increase amelioration by the greater accumulation of exosomes with therapeutic properties in compared to unmodified exosome in ischemic brain (20). Other studies have demonstrated that when exosomes loaded with different chemotherapeutic agents, PTX or Dox, they were talented to target mice tumor cells and remarkably inhibit tumor progress without observing any extent side effects $(21,22)$. In light of the evidence mentioned, putting exosomes into practice to eradicate $H$. pylori by direct and targeted antibiotics delivery in order to increase the efficiency and effectiveness is not far from mind. As in the field of infectious diseases, a group has already used exosomes to deliver intracellular antibiotic (Linezolid) for intracellular infections (by Staphylococcus aureus) in vitro and in vivo model and achieved successful results (23). Besides, it makes sense that depending on the source of the exosomes, they have distinct functions. Like that, studies have exhibited that exosomes derived from APC (antigen-presenting cells) have the potency to express the surface molecules (major histocompatibility complex) MHC I and MHC II on the cell (24). Also, Macrophage-derived exosomes play a crucial role as an inflammatory component in cardiac injury and central regulator in injury and repair, the inhibition of the progression of pathogenic microbial agents and tumor cells (25). Based on these findings, our suggestion in the direction of targeting of $H$. pylori infected cells is the using of the Macrophage-derived exosomes that able to recognize infected cells and eliminate pathogenic microbial agents and activate the innate immune response, then be loaded with these drugs against $H$. pylori. This method may be considered as an effective method to elevate the efficiency of current therapy concurrent with taking medication without side effects on gastric healthy cells.

\section{Acknowledgments}

Funding: None.

\section{Footnote}

Provenance and Peer Review: This article was a free submission to the journal. The article has undergone external peer review.

Conflicts of Interest: All authors have completed the ICMJE uniform disclosure form (available at http://dx.doi. org/10.21037/sci-2020-028). The authors have no conflicts of interest to declare.

Ethical Statement: The authors are accountable for all aspects of the work in ensuring that questions related to the accuracy or integrity of any part of the work are appropriately investigated and resolved.

Open Access Statement: This is an Open Access article distributed in accordance with the Creative Commons Attribution-NonCommercial-NoDerivs 4.0 International License (CC BY-NC-ND 4.0), which permits the noncommercial replication and distribution of the article with the strict proviso that no changes or edits are made and the original work is properly cited (including links to both the formal publication through the relevant DOI and the license). See: https://creativecommons.org/licenses/by-nc-nd/4.0/.

\section{References}

1. Suerbaum S, Michetti P. Helicobacter pylori infection. N Engl J Med 2002;347:1175-86.

2. Everhart JE. Recent developments in the epidemiology of Helicobacter pylori. Gastroenterol Clin North Am 2000;29:559-78.

3. Debraekeleer A, Remaut H. Future perspective for potential Helicobacter pylori eradication therapies. Future Microbiol 2018;13:671-87.

4. Kamarehei F, Khabiri A, Saidijam M, et al. Designing a novel ELISA method based on CagA, NapA recombinant antigens to increase sensitivity and specificity of Helicobacter pylori whole cell antigen detection. Gastroenterol Hepatol Bed Bench 2018;11:333.

5. Oleastro M, Ménard A. The role of Helicobacter pylori outer membrane proteins in adherence and pathogenesis. Biology (Basel) 2013;2:1110-34.

6. Shibayama K, Wachino Ji, Arakawa Y, et al. Metabolism of glutamine and glutathione via $\gamma$-glutamyltranspeptidase and glutamate transport in Helicobacter pylori: possible significance in the pathophysiology of the organism. Mol Microbiol 2007;64:396-406.

7. Leja M, Axon A, Brenner H. Epidemiology of Helicobacter pylori infection. Helicobacter 2016;21 Suppl 
$1: 3-7$.

8. De Francesco V, Zullo A, Hassan C, et al. Mechanisms of Helicobacter pylori antibiotic resistance: An updated appraisal. World J Gastrointest Pathophysiol 2011;2:35.

9. Keeney KM, Yurist-Doutsch S, Arrieta MC, et al. Effects of antibiotics on human microbiota and subsequent disease. Annu Rev Microbiol 2014;68:217-35.

10. Boulangé CL, Neves AL, Chilloux J, et al. Impact of the gut microbiota on inflammation, obesity, and metabolic disease. Genome Med 2016;8:42.

11. Romero-Calle D, Guimarães Benevides R, Góes-Neto A, et al. Bacteriophages as Alternatives to Antibiotics in Clinical Care. Antibiotics (Basel) 2019;8:138.

12. Tao SC, Guo SC, Zhang CQ. Modularized extracellular vesicles: the dawn of prospective personalized and precision medicine. Adv Sci (Weinh) 2018;5:1700449.

13. Thakur BK, Zhang H, Becker A, et al. Double-stranded DNA in exosomes: a novel biomarker in cancer detection. Cell Res 2014;24:766-9.

14. Ha D, Yang N, Nadithe V. Pharmaceutica Sinica AB. Exosomes as therapeutic drug carriers and delivery vehicles across biological membranes: current perspectives and future challenges. Acta Pharm Sin B 2016;6:287-96.

15. Mishra B, Patel BB, Tiwari S. Colloidal nanocarriers: a review on formulation technology, types and applications toward targeted drug delivery. Nanomedicine 2010;6:9-24.

16. Luan X, Sansanaphongpricha K, Myers I, et al. Engineering exosomes as refined biological nanoplatforms for drug delivery. Acta Pharmacol Sin 2017;38:754-63.

17. Goh WJ, Zou S, Ong WY, et al. Bioinspired Cell-Derived

doi: $10.21037 /$ sci-2020-028

Cite this article as: Khoei SG, Sadeghi H, Saidijam M. The use of exosome carrier to augmentation of Helicobacter pylori infection treatment. Stem Cell Investig 2020;7:23.
Nanovesicles versus Exosomes as Drug Delivery Systems: a Cost-Effective Alternative. Sci Rep 2017;7:14322.

18. Samanta S, Rajasingh S, Drosos N, et al. Exosomes: new molecular targets of diseases. Acta Pharmacol Sin 2018;39:501-13.

19. Mandal S. Curcumin, a promising anti-cancer therapeutic: it's bioactivity and development of drug delivery vehicles. Inter J Drug Res'Technol 2017;6:14.

20. Tian T, Zhang HX, He CP, et al. Surface functionalized exosomes as targeted drug delivery vehicles for cerebral ischemia therapy. Biomaterials 2018;150:137-49.

21. Tian Y, Li S, Song J, et al. A doxorubicin delivery platform using engineered natural membrane vesicle exosomes for targeted tumor therapy. Biomaterials 2014;35:2383-90.

22. Agrawal AK, Aqil F, Jeyabalan J, et al. Milk-derived exosomes for oral delivery of paclitaxel. Nanomedicine 2017;13:1627-36.

23. Yang X, Shi G, Guo J, et al. Exosome-encapsulated antibiotic against intracellular infections of methicillinresistant Staphylococcus aureus. Int J Nanomedicine 2018;13:8095-104.

24. De Toro J, Herschlik L, Waldner C, et al. Emerging roles of exosomes in normal and pathological conditions: new insights for diagnosis and therapeutic applications. Front Immunol 2015;6:203.

25. Wang C, Zhang C, Liu L, et al. Macrophage-Derived mir-155-Containing Exosomes Suppress Fibroblast Proliferation and Promote Fibroblast Inflammation during Cardiac Injury. Mol Ther 2017;25:192-204. 